\title{
Alpha-fetoprotein still is a valuable diagnostic and prognosis predicting biomarker in hepatitis $B$ virus infection-related hepatocellular carcinoma
}

\author{
Mingjie $\mathrm{Yao}^{1}$, Jingmin Zhao ${ }^{2}$ and Fengmin Lu ${ }^{1}$ \\ ${ }^{1}$ State Key Laboratory of Natural and Biomimetic Drugs, Department of Microbiology and Infectious Disease Center, School \\ of Basic Medicine, Peking University Health Science Center, Beijing, China \\ 2 Department of Pathology and Hepatology, Beijing 302 Hospital, Beijing, China \\ Correspondence to: Fengmin Lu, email: lu.fengmin@hsc.pku.edu.cn \\ Jingmin Zhao, email: jmzhao302@163.com \\ Keywords: alpha-fetoprotein (AFP), hepatitis B virus, hepatocellular carcinoma, diagnosis, Immunology and Microbiology Section, \\ Immune response, Immunity \\ Received: July 04, $2015 \quad$ Accepted: January 01, $2016 \quad$ Published: January 13, 2016
}

\section{ABSTRACT}

Use of serum alpha-fetoprotein (AFP) in clinical practices has been challenged in recent years, due to the lack of specificity and sensitivity. Here we conducted a retrospective study to evaluate the diagnostic and prognostic value of serum AFP among hepatocellular carcinoma (HCC) patients with their pathogenic features taken into consideration. The cohort for this study comprised 318 cases of hepatitis and 731 cases of cirrhosis, as well as 796 HCC patients. Using $11.62 \mathrm{ng} / \mathrm{mL}$ as a cut-off value, the positive rate of AFP test among serum hepatitis B surface antigen (HBsAg) positive HCC patients was significantly higher than that in those HBsAg negative HCC patients $(79.55 \%$ vs $56.49 \%, P<0.000)$. Similarly, the median serum AFP level in HCC patients with serum HBsAg positive was significantly higher than that in those HBsAg negative HCC patients $(423.89 \mathrm{ng} / \mathrm{ml}$ vs $40.82 \mathrm{ng} / \mathrm{ml}, P<0.000)$. In addition, Kaplan-Meier curve analysis revealed that lower preoperative AFP level implicated a much higher overall survival rate. Of note, such prognosis predicting value was only seen in those chronic HBV infection-related HCC patients, but not among the HCC patients etiologically irrelevant to HBV infection. We believe that serum AFP is of diagnosis and prognostic predicting value for HCC with chronic HBV infection, and strongly suggest use of serum AFP as a biomarker in China and other HBV infection endemic area like Southeast Asia.

\section{INTRODUCTION}

For decades, serum alpha-fetoprotein (AFP) is the most commonly used surveillance test for hepatocellular carcinoma (HCC) [1]. However, in recent years, use of serum AFP as a diagnosis and/or prognosis biomarker in HCC surveillance has been challenged in developed countries, due to the lack of specificity and sensitivity. Therefore, serum AFP measurement was no more recommended by European Association for the Study of the Liver (EASL) and American Association for the Study of Liver Diseases (AASLD) [2, 3]. In addition, some experts also questioned it as a valuable survival predicting biomarker.

It has been noticed that the incidence and etiology of HCC vary geographically and with different population. Recently, the etiological difference of serum AFP level between HBV and non-HBV infection-related HCC has been noticed by Chang Liu et al [4]. In addition, role of HBV x protein $(\mathrm{HBx})$ on the up-regulation of alphafetoprotein receptor (AFPR) and AFP expression has been noticed in HBV-mediated liver cancer [5]. Our own data also suggested that viral co-transcription factor HBx could directly bind to and activate the promoter of AFP gene [6]. Based on these facts, it is reasonable to postulate that the serum AFP could still be a valuable biomarker in HBV infection-related $\mathrm{HCC}$ patients.

In this study, we conducted a retrospective study to evaluate the diagnostic and prognostic value of serum AFP measurement in Chinese HCC patients with different 
Table 1: Characteristics of patients in the present study

\begin{tabular}{|c|c|c|c|c|c|}
\hline \multicolumn{2}{|l|}{ Factors } & Hepatitis & Cirrhosis & HCC & $P$ \\
\hline \multicolumn{6}{|c|}{ HBsAg $(+)$} \\
\hline \multirow{2}{*}{ Gender } & Male & $141(81.03 \%)$ & $373(80.56 \%)$ & $547(88.80 \%)$ & 0.000 \\
\hline & Female & $33(18.97 \%)$ & $90(19.44 \%)$ & $69(11.20 \%)$ & \\
\hline Age & Mean \pm sd & $42.28 \pm 11.24$ & $49.43 \pm 10.57$ & $52.02 \pm 9.86$ & 0.000 \\
\hline \multicolumn{6}{|c|}{ HBsAg(-) } \\
\hline \multirow{2}{*}{ Gender } & Male & $81(56.25 \%)$ & 197(73.51\%) & 128(71.11\%) & 0.001 \\
\hline & Female & $63(43.75 \%)$ & $71(26.49 \%)$ & $52(28.89 \%)$ & \\
\hline Age & Mean \pm sd & $47.13 \pm 11.77$ & $53.60 \pm 10.49$ & $57.02 \pm 11.09$ & 0.000 \\
\hline Total & $\mathbf{N}$ & 318 & 731 & 796 & \\
\hline
\end{tabular}

pathogenic features. Our results suggested that, despite all the pitfalls mentioned above, AFP is still a valuable biomarker for HCC diagnosis and for prognosis predicting in HBV infection-related HCC patients.

\section{RESULTS}

A total of 1845 patients diagnosed either with chronic hepatitis, cirrhosis or HCC with different backgrounds were enrolled between December 2008 and December 2013 at Henan Cancer Hospital in Zhengzhou, and Beijing 302 Hospital (Figure 1). The cohort comprised 1467 (79.51\%) males and 378 females (20.49\%), including 318 cases of hepatitis (HBsAg+, $n=174$; HBsAg-, $n=$ 144), 731 cases of cirrhosis ( $\mathrm{HBsAg}+, n=463$; HBsAg-, $n=268$ ) and $796 \mathrm{HCC}$ cases (HBsAg+, $n=616$; HBsAg-, $n=180)$ (Table 1).

Receiver operating characteristic (ROC) curves were plotted to identify a cut-off value that would best distinguish HCC patients from the other two groups of subjects. As showed in Figure 2, the optimal cut-off value for AFP was $11.62 \mathrm{ng} / \mathrm{ml}$, which yielded a sensitivity of $74.94 \%$, specificity of $86.29 \%$ and Youden index was 0.61 , the area under the ROC curve was $0.866(95 \% \mathrm{CI}$, $0.848-0.884, P<0.000)$. Using $11.62 \mathrm{ng} / \mathrm{mL}$ as the cut-off value of AFP level, the positive rate in $\mathrm{HBsAg}$ positive HCC patients was significantly than those HCC patients who were serum HBsAg negative $(79.55 \%$ vs $56.49 \%, P$ $<0.000$ ), when the etiological difference was taken into consideration. In line with this, with intervals set at $>20 \mathrm{ng} /$ $\mathrm{ml},>200 \mathrm{ng} / \mathrm{ml}$ and $>400 \mathrm{ng} / \mathrm{ml}$, the positive rates among those serum HBsAg positive HCC patients were $72.7 \%$, $56.0 \%$ and $50.6 \%$, respectively. Whereas, it dropped to $51.6 \%, 36.7 \%$ and $32.2 \%$ among those HCC patients who were serum HBsAg negative. The difference between the serum HBsAg posive and negative groups is of statistical significance $(\mathrm{P}<0.000)$. And the median serum AFP level in HCC patients with serum HBsAg positive was significantly higher than that in those who were HBsAg negative (423.89ng $/ \mathrm{ml} v s .40 .82 \mathrm{ng} / \mathrm{ml}, P<0.000)$. These results suggested that serum AFP levels were significantly elevated in a majority of HCC patients etiologically associated with chronic HBV infection.

Additionally, the prognostic predicting value of AFP was evaluated through Kaplan-Meier method among a sub-cohort of $796 \mathrm{HCC}$ patients who had underwent hepatectomy and had been followed up for a median of 34 months. As expected, lower preoperative AFP implicated a much higher overall survival rate among those HCC patients with evidence of chronic HBV infection (Figure 3). Of note, such prognostic predicating role of AFP was not seen in HCC patients without evidence of chronic HBV infection.

To investigate the risk factors for poor prognosis after surgical treatment further, univariate analysis and multivariate analysis (Cox regression) were performed with different pathogenic features taken into consideration. Univariate analysis showed that AFP value, tumor size, Gamma Glutamyl Transpeptidase (GGT) value, Alkaline phosphatase (ALP) value, and international normalized ratio (INR) value were independent risk factors affecting postoperative survival time among those $\mathrm{HBsAg}$ positive $\mathrm{HCC}$ patients. Interestingly, while among those $\mathrm{HBsAg}$ negative HCC patients, Barcelona Clinic Liver Cancer (BCLC) stage, INR value and Albumin (ALB) value, but not AFP value, were the independent risk factors affecting postoperative survival time. While the multivariate analysis revealed that AFP value, in together with INR value, GGT value, ALP value and tumor size, were the independent risk factors affecting overall post-surgery survival among those $\mathrm{HBsAg}$ positive HCC patients. While BCLC stage, INR value and ALB value were the independent risk factors for those HBsAg negative HCC patients (Table 2).

\section{DISCUSSION}

To date, the curative treatments of HCC include surgical resection, liver transplantation, TACE and RFA, etc. In order to improve patients' prognosis and long-term 
Table 2: Univariate and multivariate analysis for predictors of death

\begin{tabular}{|c|c|c|c|c|c|c|}
\hline \multirow{2}{*}{ Risk Factor } & \multicolumn{3}{|c|}{ HBsAg positive } & \multicolumn{3}{|c|}{ HBsAg negative } \\
\hline & $H R$ & $95 \% C I$ & P Value & $H R$ & $95 \% C I$ & P Value \\
\hline \multicolumn{7}{|l|}{ Univariate analysis } \\
\hline Sex(Male/Female) & 1.008 & $0.757-1.342$ & 0.955 & 1.236 & $0.765-1.998$ & 0.387 \\
\hline Age & 1.032 & $0.928-1.147$ & 0.565 & 1.039 & $0.836-1.291$ & 0.732 \\
\hline No. of tumors & 1.227 & $1.117-1.349$ & 0.000 & 1.274 & $1.052-1.542$ & 0.013 \\
\hline Diolame (Present/Absent) & 0.992 & $0.939-1.048$ & 0.774 & 1.095 & $0.966-1.241$ & 0.154 \\
\hline Tumor size & 1.321 & $1.223-1.426$ & 0.000 & 1.055 & $0.893-1.247$ & 0.526 \\
\hline BCLC & 1.196 & $1.068-1.340$ & 0.002 & 1.568 & $1.227-2.004$ & 0.000 \\
\hline ALT & 1.009 & $0.982-1.036$ & 0.519 & 1.048 & $0.834-1.316$ & 0.688 \\
\hline AST & 1.022 & $1.002-1.041$ & 0.029 & 1.292 & $1.075-1.552$ & 0.006 \\
\hline ALP & 1.152 & $1.107-1.200$ & 0.000 & 1.086 & $1.032-1.143$ & 0.002 \\
\hline GGT & 1.012 & $1.009-1.015$ & 0.000 & 1.007 & $1.000-1.013$ & 0.041 \\
\hline AFP & 1.115 & $1.072-1.159$ & 0.000 & 1.018 & $0.926-1.119$ & 0.716 \\
\hline INR & 1.932 & $1.258-2.966$ & 0.003 & 3.164 & $1.673-5.984$ & 0.000 \\
\hline ALB & 0.375 & $0.228-0.617$ & 0.000 & 0.178 & $0.040-0.805$ & 0.025 \\
\hline \multicolumn{7}{|l|}{ Multivariate analysis } \\
\hline BCLC & & & & 1.532 & $1.176-1.997$ & 0.002 \\
\hline AFP & 1.460 & 1.156 to 1.845 & 0.002 & & & \\
\hline Tumor size & 1.240 & 1.103 to 1.394 & 0.000 & & & \\
\hline GGT & 1.010 & 1.004 to 1.016 & 0.001 & & & \\
\hline ALP & 1.102 & 1.017 to 1.195 & 0.018 & & & \\
\hline INR & 1.806 & 1.140 to 2.861 & 0.012 & 3.491 & $1.874-6.052$ & 0.000 \\
\hline ALB & & & & 0.186 & $0.040-0.864$ & 0.032 \\
\hline
\end{tabular}

Abbreviation: $\mathrm{BCLC}=$ Barcelona Clinic Liver Cancer, ALT $=$ Alanine Transaminase, AST $=$ Glutamic oxalacetic transaminase, $\mathrm{ALP}=$ Alkaline phosp, GGT = Gamma Glutamyl Transpeptidase, $\mathrm{AFP}=$ Alpha-fetoprotein, $\mathrm{INR}=$ International normalized ratio, $\mathrm{ALB}=\mathrm{Albumin}$.

survival, early diagnosis of HCC is essential to implement curative interventions [7]. Despite the disadvantage of low sensitivity, low specificity and limited accuracy in HCC early diagnosis, AFP has still been recommended as a serum biomarker for diagnosis of $\mathrm{HCC}$ in clinical practice in China, which accounts for more than $55 \%$ of annually diagnosed $\mathrm{HCC}$ patients.

A variety of factors have been reported affecting the prognosis of patients with $\mathrm{HCC}[3,8,9]$. To provide evidence supporting the use of AFP measurement in clinical practices, particularly in China, here we evaluated the value of serum AFP measurement in clinical practices, with etiological differences of HCC development taken into consideration. Indeed, a majority (79.55\%) of HCC patients with serum HBsAg positive had serum AFP levels greater than $11.62 \mathrm{ng} / \mathrm{ml}$, while which dropped to $56.49 \%$ in the HCC patients irrelevant to HBV infection.
Additionally, among the HBV infection-related patients, the median serum AFP level in HCC patient group was significantly higher than that in CHB or cirrhosis patient (423.89ng/ml vs 40.82ng/ml, $P<0.000$ ). Consistent with our observation, a report from Europe has indicated the different levels of serum AFP between HCC patients with and without HBV infection [10]. These results suggested that serum AFP levels are of diagnostic value for HCC patients with chronic HBV infection. This suggestion was supported by several recent studies which approved the predictive value of elevated serum AFP for the longterm risk of $\mathrm{HCC}$ development in chronic HBV infected patients $[11,12]$.

Serum biomarkers are attractive potential tools for HCC early diagnosis because they will enable noninvasive, objective and reproducible assessments. Considering the differences of tumorigenesis and clinical 


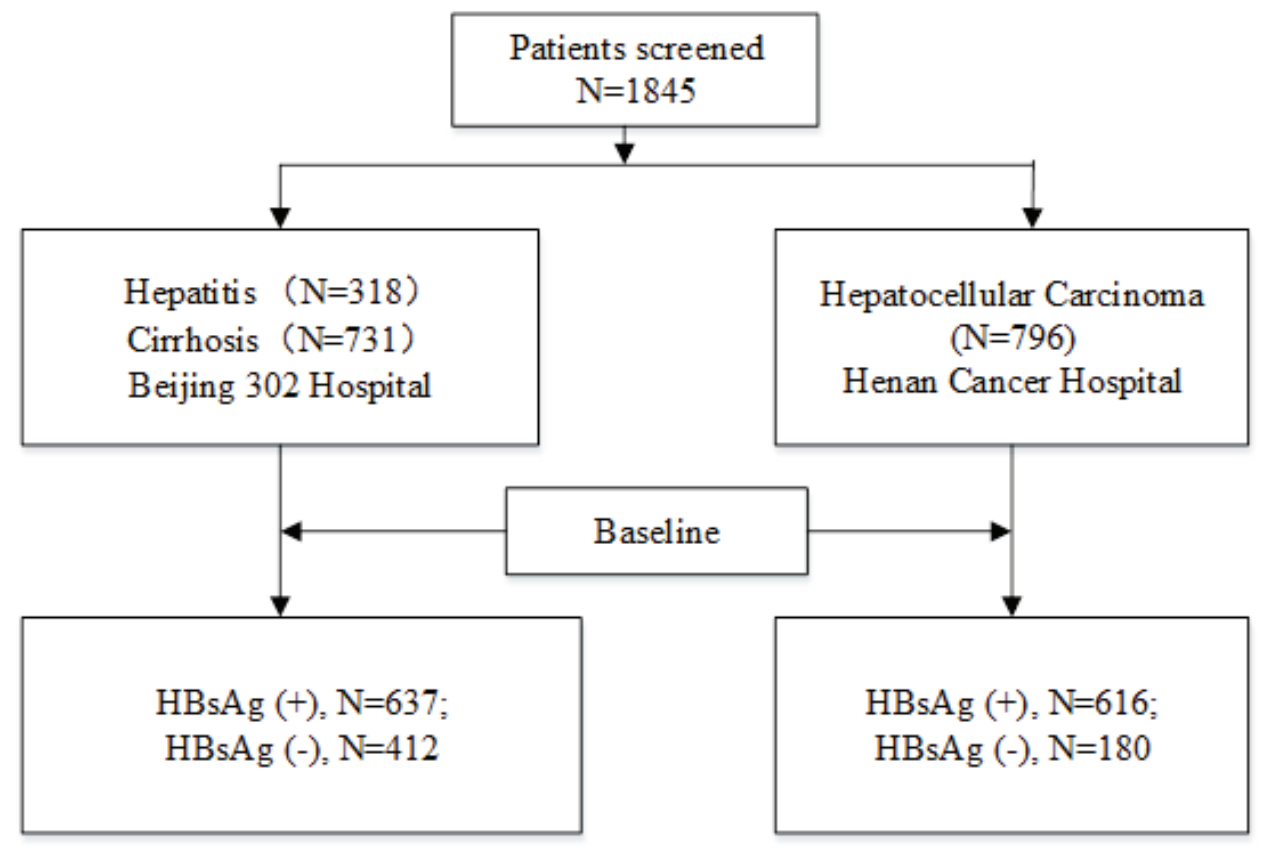

Figure 1: Patients' flowchart, data provided in absolute numbers.

\section{ROC Curve of AFP for the Diagnosis of HCC}

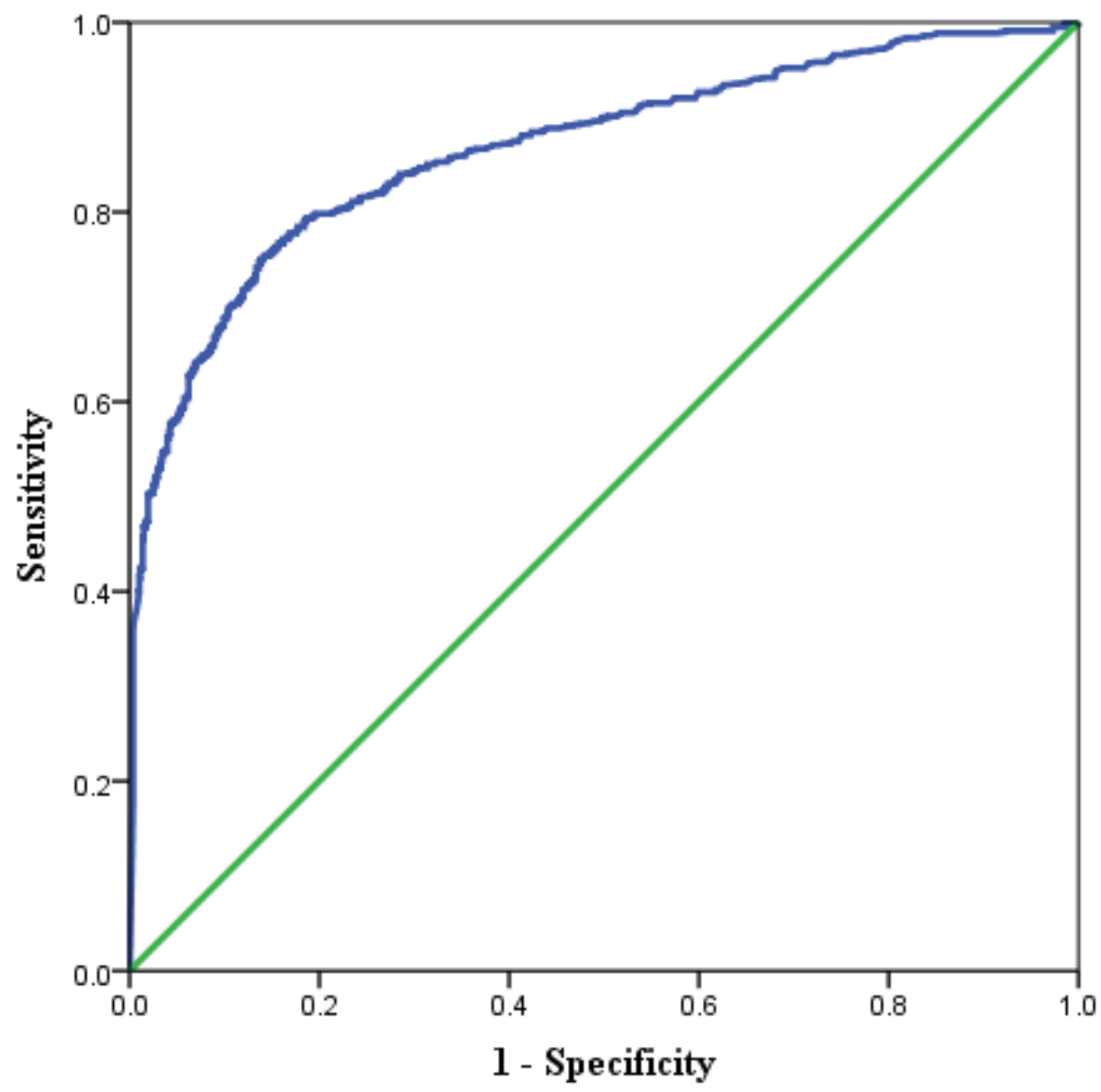

Figure 2: The receiver operating characteristic (ROC) curve of AFP in HCC diagnosis for all subjects. The points in the ROC curve indicate different AFP values with corresponding sensitivity and specificity, from which $11.62 \mathrm{ng} / \mathrm{mL}$ was chosen as the cut-off value for AFP. 
A
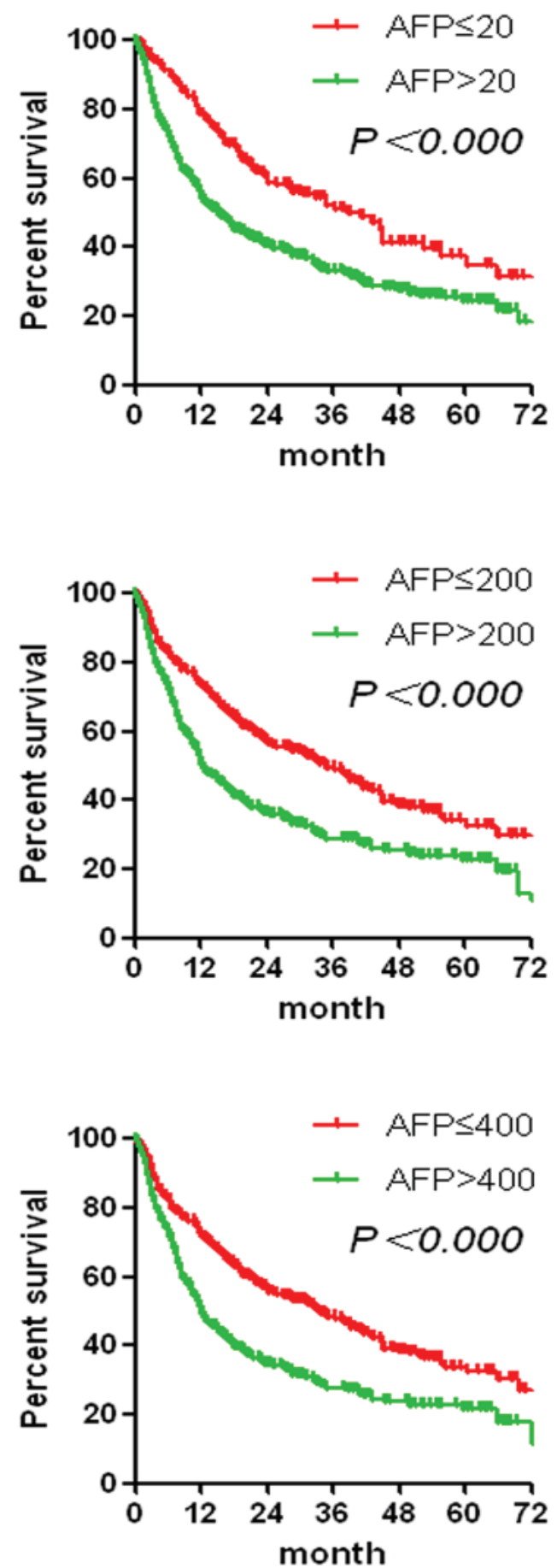

B
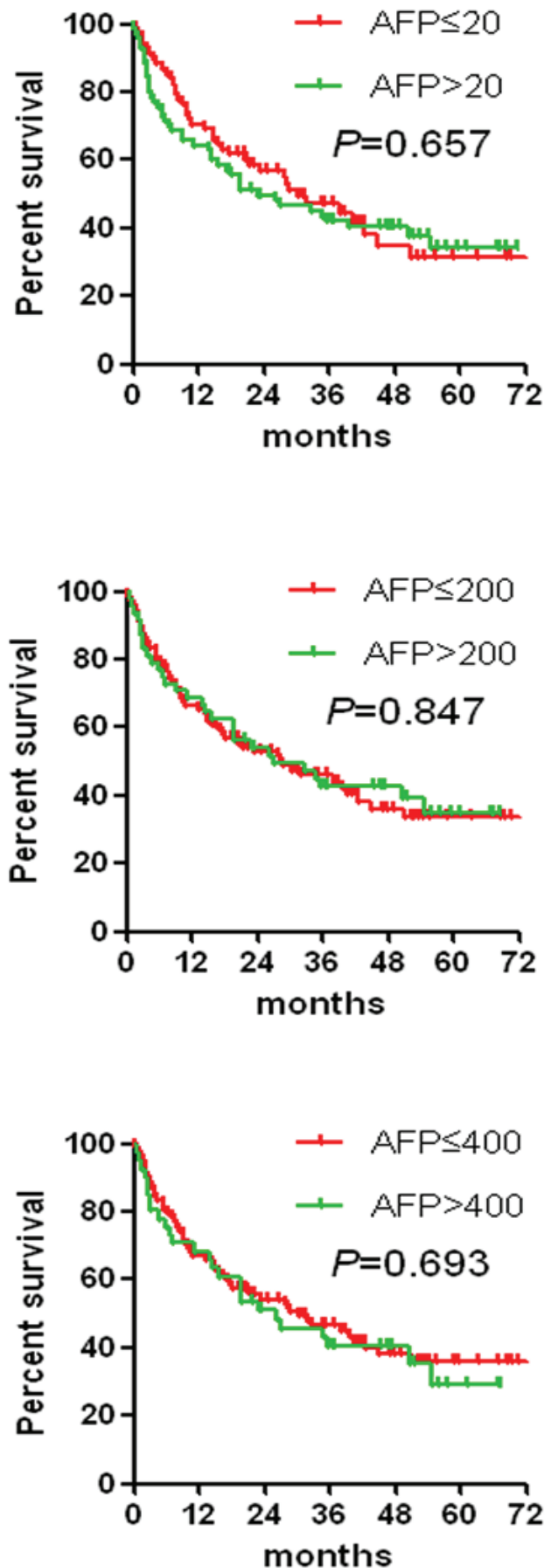

Figure 3: Cumulative post-surgery overall survival by different AFP levels among HCC patients with serum HBsAg positive (A) or with serum HBsAg negative (B). A. Cumulative incidence of HCC with HBV by different AFP levels. Comparison of cumulative survival among $(0 \sim 20 \mathrm{ng} / \mathrm{ml}$ and $>20 \mathrm{ng} / \mathrm{ml}, 0 \sim 200 \mathrm{ng} / \mathrm{ml}$ and $>200 \mathrm{ng} / \mathrm{ml}, 0 \sim 400 \mathrm{ng} / \mathrm{ml}$ and $>400 \mathrm{ng} / \mathrm{ml})$ subgroups of patients. The cumulative survival probability of the patients at 1,3 , and 5 years were $65.49 \%, 42.96 \%$ and $30.51 \%(0 \sim 20 \mathrm{ng} / \mathrm{ml}, n=168), 40.35 \%$, $25.69 \%$ and $13.78 \%(>20 \mathrm{ng} / \mathrm{ml}, n=448), 57.48 \%, 39.39 \%$ and $26.31 \%(0 \sim 200 \mathrm{ng} / \mathrm{ml}, n=271), 36.37 \%, 22.86 \%$ and $11.77 \%(>200 \mathrm{ng} /$ $\mathrm{ml}, n=345), 56.4 \%, 39.50 \%$ and $24.48 \%(0 \sim 400 \mathrm{ng} / \mathrm{ml}, n=304), 35.10 \%, 20.71 \%$ and $11.94 \%(>400 \mathrm{ng} / \mathrm{ml}, n=312)$ respectively. B. Cumulative incidence of HCC with non-HBV by different AFP levels. Comparison of cumulative survival among $(0 \sim 20 \mathrm{ng} / \mathrm{ml}$ and $>20 \mathrm{ng} /$ $\mathrm{ml}, 0 \sim 200 \mathrm{ng} / \mathrm{ml}$ and $>200 \mathrm{ng} / \mathrm{ml}, 0 \sim 400 \mathrm{ng} / \mathrm{ml}$ and $>400 \mathrm{ng} / \mathrm{ml}$ ) subgroups of patients. The cumulative survival probability of the patients at 1,3 , and 5 years were $56.97 \%, 31.02 \%$ and $21.59 \%(0 \sim 20 \mathrm{ng} / \mathrm{ml}, n=77), 49.51 \%, 39.06 \%$ and $32.36 \%(>20 \mathrm{ng} / \mathrm{ml}, n=103), 52.81 \%$, $32.47 \%$ and $25.06 \%(0 \sim 200 \mathrm{ng} / \mathrm{ml}, n=114), 53.71 \%, 40.11 \%$ and $31.20 \%(>200 \mathrm{ng} / \mathrm{ml}, n=66), 54.22 \%, 34.65 \%$ and $28.77 \%(0 \sim 400 \mathrm{ng} /$ $\mathrm{ml}, n=122), 50.59 \%, 37.25 \%$ and $26.08 \%(>400 \mathrm{ng} / \mathrm{ml}, n=58)$ respectively. 
features between $\mathrm{HBV}$-related $\mathrm{HCC}$ and non-HBVrelated $\mathrm{HCC}$, it is worthwhile to evaluate the prognosis predicting value of AFP in patients with HBV-related $\mathrm{HCC}$, especially in Asian countries where HBV infection is endemic and a main causative factor of HCC. Indeed, in the current study, through univariate and multivariate analysis, we identified that preoperative AFP level was an independent risk factor for poor prognosis in patients with HBV-related HCC after surgical treatment, and lower preoperative AFP value implicated a much higher overall survival rate. Of note, such prognostic predicating value was only seen among those HCC patients with evidence of chronic HBV infection, but not among the HCC patients etiologically irrelevant to HBV infection.

In conclusion, we believe that serum AFP levels are of diagnosis and prognostic value for HCC patients with chronic HBV infection. We acknowledge that the present study is of limitations and need to be confirmed in a larger sample sized, controlled, multicenter and prospective study.

\section{MATERIALS AND METHODS}

At enrollment, patient characteristics, virological, hematological, biochemical, and histological data were collected. Patients were examined for HCC by abdominal ultrasonography, dynamic CT, and/or MRI every 3-6 months. To evaluate the diagnostic and prognostic value of AFP, in this retrospective study, last time examination data of serum AFP level of non-HCC patients and data before therapy for HCC patents were collected. The measurement of AFP in the two hospitals were achieved by using same electrochemiluminescence immunoassay system Modular E170 (Roche, Mannheim, Germany), the normal range is 0 to $20 \mathrm{ng} / \mathrm{ml}$. Decisions regarding to each patient's course of treatment were made based on the treatment guidelines for HCC in China [13].The diagnosis of HCC was confirmed by pathologic examination of the resected liver specimens. HBV infection status was based on serum hepatitis B surface antigen (HBsAg). Diagnosis of cirrhosis was based on liver histology or clinical, laboratory and imaging data. All 796 HCC patients had underwent hepatectomy and were followed up for a median of 34 months. The prognostic predicting value of AFP was evaluated through Kaplan-Meier method and differences among different groups were assessed using the log-rank test.

All statistical analyses were performed using the statistical software package SPSS version 21.0 for Windows (SPSS, Chicago, Illinois, USA). All tests of significance were two-tailed and $P<0.05$ was considered statistically significant.

The study protocol was approved by the institute ethics committee, and the informed consents were obtained from all patients and donors before the start of study.

\section{FINANCIAL SUPPORT}

This work was supported by the National $\mathrm{S} \& \mathrm{~T}$ Major Project for Infectious Diseases (No.2012ZX10002005), the 973 Program (No. 2015CB554000), the National Natural Science Foundation of China (Nos. 81372603 and 81471938), and the 111 Project (B07001).

\section{CONFLICTS OF INTEREST}

No conflict of interest was disclosed in this study.

\section{REFERENCES}

1. Aghoram R, Cai P and Dickinson JA. Alpha-foetoprotein and/or liver ultrasonography for screening of hepatocellular carcinoma in patients with chronic hepatitis B. The Cochrane database of systematic reviews. 2012; 9:CD002799.

2. European Association For The Study Of The Liver; European Organisation For Research And Treatment Of Cancer. EASL-EORTC clinical practice guidelines: management of hepatocellular carcinoma. Journal of hepatology. 2012; 56:908-943.

3. Bruix $J$ and Sherman M. Management of hepatocellular carcinoma: an update. Hepatology. 2011; 53:1020-1022.

4. Liu C, Xiao GQ, Yan LN, Li B, Jiang L, Wen TF, Wang WT, Xu MQ and Yang JY. Value of alphafetoprotein in association with clinicopathological features of hepatocellular carcinoma. World journal of gastroenterology. 2013; 19:1811-1819.

5. Li M, Zhu M, Li W, Lu Y, Xie X, Wu Y and Zheng S. Alpha-fetoprotein receptor as an early indicator of $\mathrm{HBx}$ driven hepatocarcinogenesis and its applications in tracing cancer cell metastasis. Cancer letters. 2013; 330:170-180.

6. Zhang C, Chen X, Liu H, Li H, Jiang W, Hou W, McNutt MA, Lu F and Li G. Alpha fetoprotein mediates HBx induced carcinogenesis in the hepatocyte cytoplasm. International journal of cancer. 2015; 137:1818-29. doi: 10.1002/ijc.29548.

7. Amarapurkar D, Han KH, Chan HL and Ueno Y. Application of surveillance programs for hepatocellular carcinoma in the Asia-Pacific Region. Journal of gastroenterology and hepatology. 2009; 24:955-961.

8. Burrel M, Reig M, Forner A, Barrufet M, de Lope CR, Tremosini S, Ayuso C, Llovet JM, Real MI and Bruix J. Survival of patients with hepatocellular carcinoma treated by transarterial chemoembolisation (TACE) using Drug Eluting Beads. Implications for clinical practice and trial design. Journal of hepatology. 2012; 56:1330-1335.

9. Cabrera R and Nelson DR. Review article: the management of hepatocellular carcinoma. Alimentary pharmacology \& therapeutics. 2010; 31:461-476. 
10. Amaddeo G, Cao Q, Ladeiro Y, Imbeaud S, Nault JC, Jaoui D, Gaston Mathe Y, Laurent C, Laurent A, Bioulac-Sage P, Calderaro J, Zucman-Rossi J and http://orcid.org A-O. Integration of tumour and viral genomic characterisations in HBV-related hepatocellular carcinomas. Gut. 2015; 64:820829.

11. Hann HW, Fu X, Myers RE, Hann RS, Wan S, Kim SH, Au $\mathrm{N}$, Xing J and Yang H. Predictive value of alpha-fetoprotein in the long-term risk of developing hepatocellular carcinoma in patients with hepatitis B virus infectionresults from a clinic-based longitudinal cohort. European journal of cancer. 2012; 48:2319-2327.

12. Wong GL, Chan HL, Tse YK, Chan HY, Tse CH, Lo AO and Wong VW. On-treatment alpha-fetoprotein is a specific tumor marker for hepatocellular carcinoma in patients with chronic hepatitis B receiving entecavir. Hepatology. 2014; 59:986-995.

13. [Expert consensus on the scheme of pathological diagnosis of primary liver cancer.] Zhonghua Gan Zang Bing Za Zhi, [Chinese journal of hepatology.] 2011; 19:254-256. 